\title{
Resource partitioning and niche segregation in a steppe bird assemblage
}

\author{
J. Trabaํㅗ M. B. Morales, C. P. Carmona and M. Paula Delgado \\ Terrestrial Ecology Group (TEG), Department of Ecology, Universidad Autónoma de Madrid, c/ Darwin, 2. \\ E-28049 Madrid, Spain \\ ${ }^{1}$ Corresponding author: juan.traba@uam.es
}

Keywords: Community assembly, Farmland birds, Habitat selection, Microhabitat, Niche overlap, Species coexistence.

\begin{abstract}
Niche theory predicts that coexisting species will partition resources to limit the effects of interspecific competition. We examined microhabitat partitioning in six sets of steppe birds associated to agroecosystems in central Spain (female and male Great Bustards Otis tarda, female and male Little Bustards Tetrax tetrax, Red-legged Partridges Alectoris rufa and Eurasian Stone-curlews Burhinus oedicnemus) to estimate realized niche breadth, overlap and segregation. Principal Components Analysis on data from used and random microhabitat locations produced two axes we retained for analysis related with two key factors: cover-visibility and food availability. Non-parametric kernel density functions were calculated for each of the PCA axes and species (or sexes), and niche overlap estimated as the area shared between species' density functions. Null models were run to evaluate overlap significance. In analyses of microhabitat selection by the six sets of birds, 13 out of 15 pairs had significant resource partitioning and niche segregation, except for the pairs partridge and female Great Bustard and the two sexes of Great Bustard. Eurasian Stone-curlew showed wider trophic niche breadth, although segregated from the other species, probably because of its higher invertebrate requirements. Great and Little Bustards segregated in both niche axes, selecting microhabitat according to their body size. Accessibility to food resources and shelter seems to be similar for partridges and female Great Bustards, overlapping in their selection, which may indicate the existence of segregation in other niche factors (e.g., feeding habits). Great Bustard males showed niche overlap with females. Little Bustard males showed feeding microhabitat selection patterns similar to those of females, although they preferred more open microhabitats to meet their sexual display requirements. The entire assemblage had significantly less overlap than expected by chance, suggesting that differential microhabitat selection and realized niche partitioning may explain coexistence in steppe bird communities. Our results suggest that the maintenance of different microhabitat structure should be a priority in the management of agricultural environments.
\end{abstract}

Nomenclature: del Hoyo et al. (2013).

Abbreviations: CM-Camarma de Esteruelas, CR-Campo Real, GLMM-General Linear Mixed Model, PCA-Prinicipal Components Analysis, VT-Valdetorres de Jarama.

\section{Introduction}

Niche theory predicts that coexisting species will limit the effects of interspecific competition through partitioning of shared resources, which may also select for phenotypic differences (Chesson 2000). Resource partitioning may be the outcome of long-term competitive coexistence over evolutionary time that has shaped the final configuration of species assemblages (Leibold et al. 2004, but see Hubbell 2001). As a result of such processes, different species or individuals show differential success in resource exploitation (Gurd 2008, see Hromada et al. 2003). Resource partitioning may be primary, when species do not share their principal resources and are thus segregated (MacArthur and Levins 1967, Rosenzweig 1981). It may otherwise be secondary, when species overlap in their preferences for primary or most valued resources while showing partitioning with respect to less important ones (Gurd 2008, Rosenzweig and Abramsky 1986). In short, coexisting species should differ in specific aspects of their resource use (i.e., realised niche segregation, Devictor et al. 2010; see also Chase and Leibold 2003) that will allow niche packing among them (niche compression hypothesis, sensu MacArthur and Levins 1967).

Habitat selection by organisms is the result of an evolutionary compromise between different selection pressures maximizing survival or reproductive success (Krebs and Davies 1987). The relative importance of these pressures differs not just among species but also among conspecifics, especially among sexes (Morales et al. 2008, Morales and Traba 2009). Habitat represents a component of environmental availability that a species requires and selects (Chase and Leibold 2003), so the concept of habitat selection is highly entangled with that of realised niche (Whittaker et al. 1973). In the present paper, we evaluate niche partitioning as a main factor for structuring communities using a steppe bird assemblage as a case study. Steppe birds have singular ecological and evolutionary characteristics related to their 
Table 1. Height $(\mathrm{cm})$ and mass $(\mathrm{g})$ ranges, and main food resources of the study species (and sexes) (from del Hoyo et al. 2013).

\begin{tabular}{lrrc}
\hline \multicolumn{1}{c}{ Species (Sex) } & Height $(\mathrm{cm})$ & \multicolumn{1}{c}{ Mass $(\mathrm{g})$} & Main food resource \\
\hline Eurasian Stone Curlew & $40-44$ & $338-535$ & Insectivorous \\
Little Bustard (male) & 43 & $794-975$ & Herbivorous \\
Little Bustard (female) & 43 & $680-945$ & Herbivorous \\
Red-legged Partridge & $34-38$ & $391-547$ & Omnivorous \\
Great Bustard (male) & 105 & $5800-18000$ & Herbivorous \\
Great Bustard (female) & 75 & $4350(3300-5200)$ & Herbivorous \\
\hline
\end{tabular}

ground-nesting habits and their preference for structurally simple habitats (De Juana 2005). Steppes are basically open, treeless landscapes characterized by a high risk of exposure to avian predators due to high visibility. Steppe bird species are naturally associated with grassy pastures and steppes, but in Europe, particularly in Spain, they are mainly linked to agrarian environments (Suárez et al. 1997, Guerrero et al. 2011). In addition, they are of high conservation interest given the severity of their decline across the whole of Europe in recent years (Tryjanowski et al. 2011, Onrubia and Andrés 2005, Sanderson et al. 2005).

Studies on the coexistence of steppe bird species in Europe often assume resource partitioning at the macrohabitat or landscape scale (see e.g., Delgado and Moreira 2000, Sanza et al. 2012), with each species showing a preference for particular agrarian substrates, such as stubbles, cereal fields, or ploughed lands. Nevertheless, during the breeding season these species are often observed sharing the same macrohabitats, which implies that factors accounting for their coexistence operate at a smaller scale (microhabitat: see Serrano and Astraín 2005, Morales et al. 2008). In agrarian systems, microhabitat selection may be interpreted as a preference for particular vegetation structures, and it may also include additional features such as food or shelter availability (Morales et al. 2008, Morales and Traba 2009). Thus it provides a reasonable approximation to the Hutchinsonian realized niche (Chase and Leibold 2003, Devictor et al. 2010) and allows the evaluation of the degree of realized niche overlap and segregation with respect to relevant evolutionary trade-offs in the life histories of all species.

Several methods for measuring niche breadth and overlap have been applied in ecological studies (see a review in Devictor et al. 2010). In this study we chose a metric that allows using many original variables related to one or more ecological gradients (niche axes that explain coexistence), and permits the comparison among species in an assemblage. In addition, using null models to compare observed with random patterns allows estimating the actual overlap between pairs of species and for the whole assemblage (Geange et al. 2011, Chase and Leibold 2003).

Therefore, we evaluate the realised niche segregation, estimated by microhabitat selection of four steppe bird species, and the separate sexes of two of them, that are linked to agrarian environments. Following the hypothesis that two species must differ in their requirements in order to coexist locally (Chase and Leibold 2003, see however Hubbell 2001), we predicted that such species would have realised niche segregation (expressed in terms of microhabitat selection) so that interspecific overlap would be minimised, facilitating coexistence. This segregation could be expressed as either a primary or secondary microhabitat partitioning. Trade-offs could also differ between sexes, particularly in sexually dimorphic species (Morales et al. 2008). On the other hand, microhabitat overlap could be an indication of resource abundance, which limits the potential for competition. We use a novel method in this context, which allows estimating niche breadth and the significance of overlapping between pairs of species (or sexes) and in the entire assemblage.

\section{Materials and methods}

\section{Study area}

The study was conducted at three sites in the cereal pseudo-steppes of Madrid (central Spain): Valdetorres del Jarama (VT; $40.60^{\circ} \mathrm{N}, 3.41^{\circ} \mathrm{W}$ ), Camarma de Esteruelas (CM; $\left.40.56^{\circ} \mathrm{N}, 3.36^{\circ} \mathrm{W}\right)$ and Campo Real (CR; $\left.40.31^{\circ} \mathrm{N}, 3.30^{\circ} \mathrm{W}\right)$. The three sites are of high value for steppe birds based on the diversity and abundance of such species (Traba et al. 2007). They present a flat or gently undulating landscape, a continental Mediterranean climate with limited precipitation $\left(<600 \mathrm{~mm}\right.$ year $\left.{ }^{-1}\right)$ in spring and autumn, and traditional or semi-traditional agriculture, comprising cereal and leguminous crops alternating with fallows, ploughed land and setasides (long-term abandoned plots).

\section{Bird censuses}

Data were obtained during the breeding seasons (AprilMay) of years 2005 and 2006 for four species: Eurasian Stone-curlews Burhinus oedicnemus, Red-legged Partridges Alectoris rufa, Little Bustards Tetrax tetrax and Great Bustards Otis tarda. They represent the entire medium to large-sized (Table 1) steppe bird assemblage (Traba et al. 2007 ) that can potentially coexist in these areas (excluding raptors) and so constitute an assemblage that is suitable for coexistence and niche overlap evaluation. All four species are typical of open, treeless zones, where they are often found in sympatry, as was the case here for the three localities. Specific habitat selection studies are available for all of them (see Lane et al. 2001, Moreira et al. 2004, Morales et al. 2005, Morales et al. 2008, Buenestado et al. 2008, Delgado et al. 2010, López-Jamar et al. 2010, Traba et al. 2012), in which their preferences for agrarian habitats have been described. Thus, the Little Bustard usually prefers fallows, the Stonecurlew prefers set-aside areas and abandoned lands, the Great 
Table 2. Mean and Standard Deviation (SD) of vegetation structure variables measured in $1 \mathrm{~m} \times 1 \mathrm{~m}$ sampling squares $(n=420)$ and results of the Principal Components Analysis (PCA) conducted to determine independent vegetation structure variables featuring birds and random locations.

\begin{tabular}{|c|c|c|c|c|}
\hline & Mean & SD & $\begin{array}{c}\text { PCA } \\
\text { Component } 1 \\
\end{array}$ & $\begin{array}{c}\text { PCA } \\
\text { Component } 2 \\
\end{array}$ \\
\hline Bare ground covera $(\%)$ & 47.18 & 34.92 & -0.82 & -0.46 \\
\hline Litter $\operatorname{cover}^{\mathrm{a}}(\%)$ & 11.31 & 19.12 & 0.00 & 0.75 \\
\hline Total vegetation covera $(\%)$ & 46.54 & 33.91 & 0.91 & 0.27 \\
\hline Green vegetation covera $(\%)$ & 31.88 & 35.01 & 0.78 & 0.05 \\
\hline Green weed covera $(\%)$ & 18.90 & 27.73 & 0.08 & 0.83 \\
\hline Number of contacts below $5 \mathrm{~cm}$ height ${ }^{\mathrm{b}}(\mathrm{cm})$ & 0.97 & 0.95 & 0.60 & 0.62 \\
\hline Number of contacts from 5 to $10 \mathrm{~cm}$ height $(\mathrm{cm})$ & 0.18 & 0.79 & 0.77 & 0.42 \\
\hline Number of contacts from 10 a $30 \mathrm{~cm}$ height $^{\mathrm{b}}(\mathrm{cm})$ & 1.36 & 1.42 & 0.90 & 0.11 \\
\hline Number of contacts from over $30 \mathrm{~cm}$ height $(\mathrm{cm})$ & 1.01 & 1.62 & 0.82 & -0.24 \\
\hline Maximum vegetation height $(\mathrm{cm})$ & 38.51 & 29.34 & 0.78 & 0.10 \\
\hline PCA Eigenvalue & -- & -- & 5.14 & 2.16 \\
\hline PCA Cumulative $\%$ variance & -- & -- & 51.44 & 73.07 \\
\hline
\end{tabular}

a Percentage of ground within squares

b Number of contacts of vegetation with a $0.5 \mathrm{~cm}$ diameter metal rod

Bustard prefers cereals and the Red-legged Partridge selects field margins and set-asides. Despite these differences in general preferences, they are often found together in their distribution areas. In those species where sex can be differentiated due to the existence of sexual dimorphism (Great and Little Bustards, Cramp and Simmons 1980), each sex was analysed separately to detect differences in intersexual niche partitioning (see Morales et al. 2008). Both bustards and Red-legged Partridges are basically herbivorous, with a preference for leaves for bustards and seeds for the partridge; invertebrates are also in the diet of partridges, although much less important (Cramp and Simmons, 1980). Stone-curlews are mainly insectivorous, and rarely feed on seeds or plants (Cramp and Simmons 1980) (Table 1).

Male Little Bustards, and both sexes of Great Bustards, were censused by car transects throughout the three study areas making use of available roads and tracks. Stops were made every $500 \mathrm{~m}$ at which all detected individuals were recorded and geo-referenced (see Morales et al. 2008 for further details). A different (but comparable) survey method was used for female Little Bustards, as well as Stone-curlews and partridges to maximize their detection due to their smaller size and their cryptic behavior. In this case, censuses consisted of systematic surveys of 12 randomly determined $500 \mathrm{~m} \times 500$ $\mathrm{m}$ squares in each site. Each square was surveyed by a walking team of four to six experienced observers 5-10 m apart, walking a series of linear parallel transects within the square, also noting and geo-referencing individuals of all target species detected. The use of both methods for bird census has already been described (see Morales et al 2008, Morales and Traba 2009, Traba et al. 2012 for further details).

\section{Microhabitat sampling}

The microhabitat selected by each species (and sex) was characterised by sampling the structure and complexity of vegetation at all the locations where individuals were sighted $(n=242)$. Random microhabitat control locations were generated automatically using ARCGIS 9.3, using a 100 m exclusion buffer around each bird location to reduce the probability that species were using those parts of the territory. We sampled microhabitat at 178 random points, $\sim 70 \%$ of the number of bird locations. No more control points could be sampled due to the fast structural changes in microhabitat (cover and height) during the reproductive season. Microhabitat sampling was conducted no later than 7 days after bird censuses. Five $1 \mathrm{~m} \times 1 \mathrm{~m}$ quadrats were located at each microhabitat sampling point: a central quadrat at the precise sampling location and four more points placed at $10 \mathrm{~m}$ north, south, east and west from the central point. Ten vegetation variables describing horizontal and vertical structure were measured in each quadrat (Rotenberry and Wiens 1980, 2009, Davis 2004) (Table 2). Average values among the five $1 \mathrm{~m} \times 1 \mathrm{~m}$ quadrats were used for analysis (Table 2).

\section{Statistical analyses}

A Principal Components Analysis (PCA) using vegetation structure variables of observation and control points for both years and study areas was conducted to determine independent variables that could be interpreted as ecologically significant gradients. Varimax rotation was applied in order to facilitate axes interpretation. Only axes with eigenvalues $>1$ were selected. The scores of each observation for the PCA axes were used to interpret the microhabitat utilisation gradients (i.e., realised niche) for each set of birds. Interspecific and sex differences in realised niche were evaluated by means of a General Linear Mixed Models (GLMM) on selected PCA axes (after log-transformation). Factors Year (2005 and 2006) and Locality (VT, CM and CR; see Study Area) were included in the model as random factors, while type of bird was included as a fixed one. Between-set of birds differences were tested a posteriori using the Fisher LSD test (see Traba et al. 2013 , for a similar analysis). These analyses were carried out in the Statistica program (Statsoft 2007). 
Table 3. Results (probability values $\mathrm{P}$ ) of the Fisher LSD a posteriori test used to compare pairs of means after the MANOVA over the two Principal Components Analysis components (PCA Component 1: below diagonal; PCA Component 2: above diagonal). Asterisks indicate $\mathrm{P}<0.05$.

\begin{tabular}{|c|c|c|c|c|c|c|c|c|}
\hline & \multirow[b]{2}{*}{ Species (sex) } & \multicolumn{7}{|c|}{ Component 2} \\
\hline & & Control & $\begin{array}{c}\text { Eurasian } \\
\text { Stone-curlew }\end{array}$ & $\begin{array}{l}\text { Great Bustard } \\
\text { (female) }\end{array}$ & $\begin{array}{l}\text { Great Bustard } \\
\text { (male) }\end{array}$ & $\begin{array}{l}\text { Red-legged } \\
\text { Partridge }\end{array}$ & $\begin{array}{l}\text { Little Bustard } \\
\text { (female) }\end{array}$ & $\begin{array}{l}\text { Little Bustard } \\
\text { (male) }\end{array}$ \\
\hline \multirow{7}{*}{ 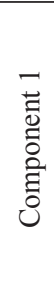 } & Control & --- & $<0.01^{*}$ & 0.36 & 0.30 & $<0.01 *$ & $<0.01^{*}$ & $<0.01 *$ \\
\hline & Eurasian Stone- curlew & $<0.01 *$ & --- & $<0.01 *$ & $<0.01 *$ & $<0.01 *$ & $0.02 *$ & $<0.01 *$ \\
\hline & Great Bustard (female) & $0.03 *$ & $<0.01 *$ & --- & 0.14 & 0.05 & $0.03 *$ & $0.02 *$ \\
\hline & Great Bustard (male) & 0.49 & $<0.01 *$ & 0.26 & --- & $<0.01 *$ & $<0.01 *$ & $<0.01^{*}$ \\
\hline & Red-legged Partridge & 0.62 & $<0.01 *$ & 0.13 & 0.80 & --- & 0.73 & 0.91 \\
\hline & Little Bustard (female) & 0.11 & $<0.01 *$ & 0.53 & 0.56 & 0.35 & --- & 0.77 \\
\hline & Little Bustard (male) & 0.28 & $<0.01 *$ & $0.01 *$ & 0.19 & 0.23 & $0.03 *$ & --- \\
\hline
\end{tabular}

We used a complementary analysis to estimate niche breadth and overlap between pairs of species and sexes, and for the entire assemblage. We estimated a non-parametric kernel density function per PCA axis and set of birds, using a method developed for the estimation of functional trait distances among species (Mouillot et al. 2005). According to this, niche overlap (either for pairs of species or for the entire assemblage) can be estimated as the area under overlapping kernel density functions of different species (i.e., under the smaller of different species' specific density functions, Mouillot et al. 2005, Geange et al. 2011, Mason et al. 2011). The use of kernel distributions avoids the assumption that the values of species in the PCA axes are normally distributed and provides a better estimation of the overlap among species than Gaussian distributions (Mouillot et al. 2005). In order to evaluate if observed overlap is different from random overlap, we followed the null-modelling approach proposed by Geange et al. (2011). In this approach, the observations of all the possible pairs of set of birds are pooled, and the set of birds' labels are randomized, to test the null hypothesis of no niche differentiation between pairs of species and sexes. Additionally, we performed a similar simulation with all the set of birds together to evaluate the niche overlap for the whole community. We performed a total of 10,000 randomizations for each pair of species and for the whole community, calculating each time the overlap between the simulated probability density distributions. This procedure allowed us to calculate a p-value for each of these parameters by ranking the observed overlap value against the simulated values. Significant differences for a pair or for the whole assemblage imply that the observed overlap is significantly smaller than that expected by random (i.e., segregation).

Afterwards, in order to determine the overlap in the most preferred microhabitats we characterized the core area for each species (or sex) and PCA axis. We defined the core area of a species as the narrowest interval (or intervals in the case of multimodal density distributions) in the PCA axis that encloses $50 \%$ of the species' density distribution. We estimated niche breadth for each species as the distance between coordinates defining its core area. Thus, units of niche breadth are the same as the original PCA axis and are thus comparable among species. The $50 \%$ core area avoids the effect of outliers, using only the more consistent locations in the definition of the niche breadth (Worton 1989). Finally, to define the common realised niche for the entire assemblage, we calculated axis intervals at which all sets of birds were present, i.e., the extremes of the overlapping area for the six density distributions. To calculate the overlap among species and for the whole assemblage we used the 'trova' function (De Bello et al. 2013) in the R environment (v.2.13.1, R Development 2011)

\section{Results}

The PCA of the vegetation structure variables extracted two axes after Varimax rotation with eigenvalues $>2$, that together accounted for $73 \%$ of the variance (Table 2 ). The first axis $(51,44 \%$ of the variance) was negatively associated with bare ground cover and positively associated with total vegetation cover, with green vegetation cover, with the number of contacts from 5 to $10 \mathrm{~cm}$ height, with the number of contacts from 10 to $30 \mathrm{~cm}$ height and with the number of contacts from over $30 \mathrm{~cm}$ height. This axis may be interpreted in terms of a visibility/cover gradient because it distinguishes areas with high plant cover and vegetation density from those with a large extent of bare ground. The second axis $(21.63 \%$ of the variance) was positively associated with green weed cover and litter cover. This axis may be interpreted in terms of a food availability gradient because weeds comprise a high proportion of the diet of most of the study species (Cramp and Simmons 1980, Green 1984, Lane et al. 1999, Jiguet 2002). On the other hand, substrates with large amounts of litter tend to offer a greater abundance of arthropods (Clere and Bretagnolle 2001), which is the principal diet element of the Stone-curlew (Green et al. 2000, Giannangeli et al. 2004), as well as an important diet component for the other species during the breeding season (Green 1984, Lane et al. 1999, Jiguet 2002). Thus, as a whole, these two PCA axes may be interpreted as realised niche axes in a Hutchinsonian mode.

GLMM results showed that Locality was not significant for any of the PCA axes (First axis: $\mathrm{F}=0.8453 ; P=0.430$; Second axis: $\mathrm{F}=0.087 ; P=0.610$ ), while Year showed significant differences only for the First axis (First axis: $\mathrm{F}=5.093$; $P<0.05$; Second axis: $\mathrm{F}=0.770 ; P=0.381)$. GLMM showed significant differences between sets of birds and control locations for both axes (First axis: $\mathrm{F}=5.396 P<0.0001$; Second axis: $\mathrm{F}=10.210 ; P<0.0001)$, indicating that together these sets 
Figure 1. Centroids of species' observations for the four species and for control locations $( \pm$ SE) within the space defined by the first two PCA axes (after Varimax rotation).

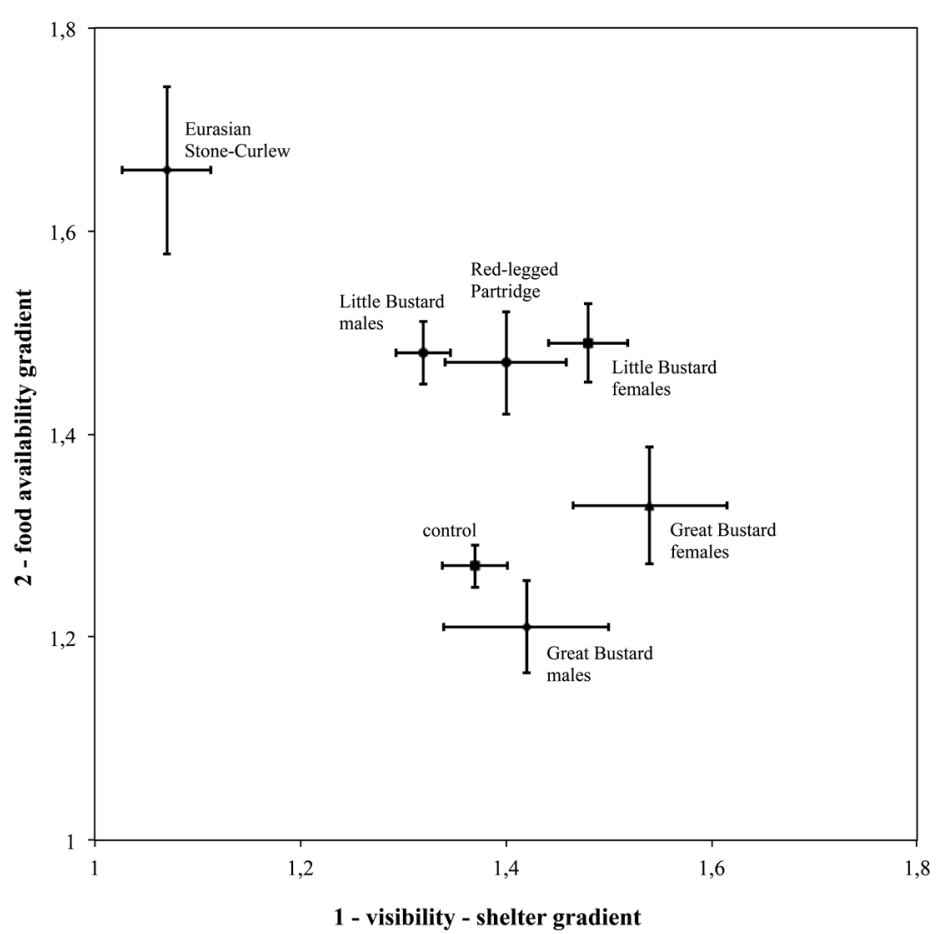

of birds exhibit differences in their realised niche (Figure 1). The a posteriori Fisher LSD analysis of the first axis showed differences from control points only for Stone-curlews and female Great Bustards (Table 3). Nevertheless, for the second axis, differences from control points were found for all sets of birds except for both sexes of the Great Bustard (Table 3 and Figure 1).

The a posteriori test also enables discrimination between sets of birds (Table 3). Thus, the Stone-curlew had a characteristic microhabitat use pattern (realised niche) that differed from the other birds for both axes, occupying an exclusive space defined by high food and low cover availability (Figure 1). The Red-legged Partridge, and both Little Bustard males and females, occupied the centre of the space defined by both axes. Male and female Little Bustards selected locations that were very similar to those selected by partridges, especially in relation to food availability; male Little Bustards showed different habitat selection patterns from Great Bustards both in relation to cover (with females) and to food availability (with both sexes; Figure 1 and Table 3). Finally, Great Bustard locations were characterised by a subspace dominated by high cover availability but with low food availability (Figure 1).

The results of the analyses of overlap between set of birds' density functions supported the previous analyses, clarifying the patterns about species segregation and overlap. The Stone-curlew was the species with more marked speciesspecific preferences, having low mean overlap with the other species $(51.9 \%$ for the first axis; $65.7 \%$ for the second one; $58.8 \%$ for the grand mean; Figure 2). In contrast, Red-legged Partridge was the species with the largest mean overlap with the other species (grand mean: 76.2\%; Figure 2). But in general, all the pairwise overlaps between species were very similar and apparently high (grand mean $=66.7 \%$; Figure 2 ).
Table 4. Niche breadth per set of birds, for the two gradients: cover-visibility, and food availability. Niche breadth is estimated as the distance between coordinates defining each $50 \%$ core area. Units of niche breadth are the same as in the original PCA axis and must be used in between-species comparative terms

\begin{tabular}{lcc}
\hline \multicolumn{1}{c}{ Species (sex) } & $\begin{array}{c}\text { Cover-visibility } \\
\text { niche breadth }\end{array}$ & $\begin{array}{c}\text { Food availability } \\
\text { niche breadth }\end{array}$ \\
\hline Eurasian Stone Curlew & 0.34 & 0.63 \\
Great Bustard (female) & 0.56 & 0.42 \\
Great Bustard (male) & 0.63 & 0.23 \\
Red-legged Partridge & 0.64 & 0.44 \\
Little Bustard (female) & 0.31 & 0.32 \\
Little Bustard (male) & 0.28 & 0.43 \\
\hline
\end{tabular}

The results of the null models showed that nearly all the pairs of species had an overlap significantly smaller than expected from random, for both of the axes or at least for one of them, which indicates a niche segregation pattern (Figure 2). Only the pairs Red-legged Partridge / Great Bustard female, and Great Bustard male / Great Bustard female did not show niche segregation (Figure 2). The rest of the pairs supported the hypothesis of niche segregation in a competitively structured assemblage. Moreover, eight pairs out of 15 showed segregation in both components, 4 out of 15 in just the first one, and only one pair (Red-legged Partridge / Great Bustard male) showed segregation just in the second component (Figure 2).

The examination of the core areas showed marked bimodality for Red-legged Partridge and Great Bustard male, while the others had unimodal core areas (Figure 2). Differences in the distribution of core areas could have favoured significance of segregation. For instance, the valley of the bimodal distribution of Great Bustard and Partridge coincided with the peak of the distributions of both sexes of Little Bustards 
(Figure 2); accordingly, null models indicated the existence of niche segregation between bustard species. Compared with males, female Little Bustards had a relatively greater preference for microhabitats with high cover availability, and a smaller niche overlap with the rest of species (Table 4).

The results of the null models for the entire assemblage showed a significantly smaller overlap among set of birds than the randomly expected one, which indicates a community structured by competitive interactions (Figure 3 ). The common niche for the entire assemblage, that is, the overlapping area of all the six species and sexes together, was $31.34 \%$ and $40.28 \%$ for axis 1 and 2, respectively, much lower than random expectations (axis 1: $69.10 \% \pm 5.81 \%$; axis $2: 68.64 \% \pm$ $5.90 \%$, after 10000 iterations; $P<0.001$; Figure 3).
Red-legged Partridges had the largest cover niche breadth (i.e., generalist) while Little Bustard males showed the smallest one (specialist) (Table 4). In contrast with its rather small cover availability requirements, among the studied set of birds the Stone-curlew had the largest breadth for food availability, while in this case the male Great Bustard was the most specialized (Table 4).

\section{Discussion}

The present study provides empirical evidence for realised niche packing during the breeding season according to the microhabitat selection (i.e., realised niche) of four species and the separate sexes of two of them. This arrangement

\section{FACTOR 1 (Refuge availability)}
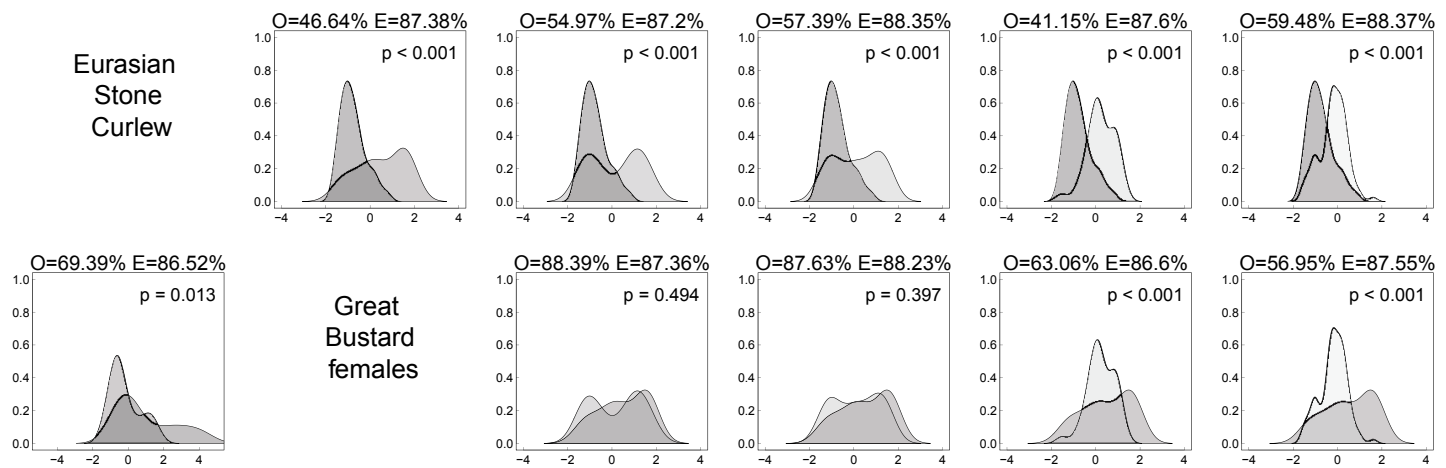

Great

Bustard

females
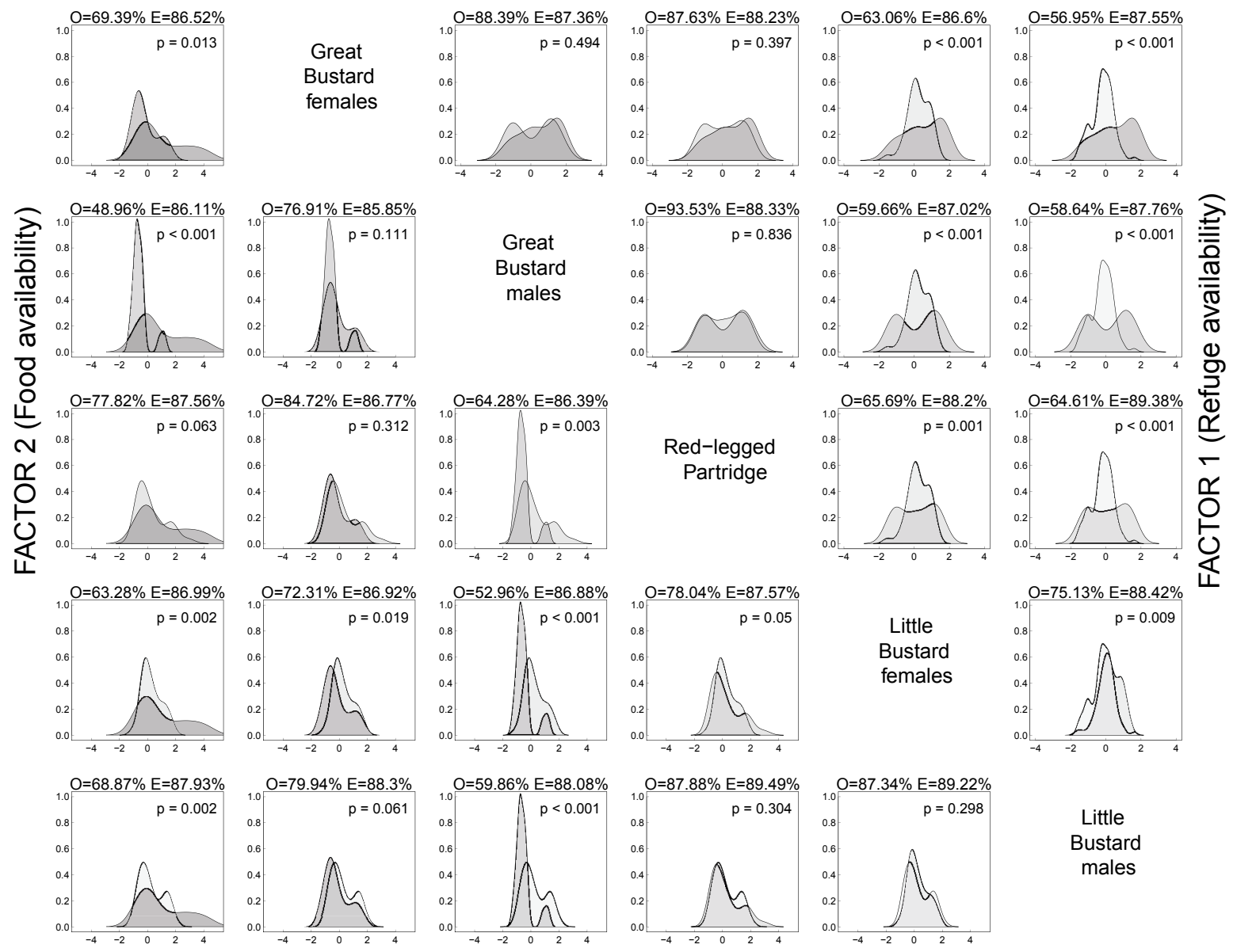

\section{FACTOR 2 (Food availability)}

Figure 2. Overlap between probability density distributions of all the possible pairs of studied species in the PCA axis 1 (Cover availability; above the diagonal) and the PCA axis 2 (Food availability; under the diagonal). For each plot, observed (O) and expected (E) overlap areas (expressed as percentages) as well as the corresponding p-value are shown. For each pair of species and axis, different gray levels indicate different species. 
Table 5. Summary of resource partitioning in all species pairs according to their segregation along microhabitat axes.

\begin{tabular}{|c|c|c|c|c|}
\hline Species pairs & $\begin{array}{l}\text { First axis } \\
\text { segregation? }\end{array}$ & $\begin{array}{l}\text { Second axis } \\
\text { segregation? }\end{array}$ & $\begin{array}{l}\text { Validate niche } \\
\text { segregation hy- } \\
\text { pothesis? }\end{array}$ & $\begin{array}{l}\text { Type of resource } \\
\text { partition }\end{array}$ \\
\hline $\begin{array}{l}\text { Little Bustard female } \\
\text { / Eurasian Stone-curlew }\end{array}$ & YES & YES & YES & Primary \\
\hline $\begin{array}{l}\text { Little Bustard female / } \\
\text { Great Bustard female }\end{array}$ & YES & YES & YES & Primary \\
\hline $\begin{array}{l}\text { Little Bustard female / } \\
\text { Great Bustard male }\end{array}$ & YES & YES & YES & Primary \\
\hline $\begin{array}{l}\text { Little Bustard female / } \\
\text { Red-legged Partridge }\end{array}$ & YES & YES & YES & Primary \\
\hline $\begin{array}{l}\text { Little Bustard male / } \\
\text { Eurasian Stone-curlew }\end{array}$ & YES & YES & YES & Primary \\
\hline $\begin{array}{l}\text { Little Bustard male / } \\
\text { Great Bustard female }\end{array}$ & YES & NO & YES & Primary \\
\hline $\begin{array}{l}\text { Little Bustard male / } \\
\text { Great Bustard male }\end{array}$ & YES & YES & YES & Primary \\
\hline $\begin{array}{l}\text { Little Bustard male / } \\
\text { Little Bustard female }\end{array}$ & YES & NO & YES & Primary \\
\hline $\begin{array}{l}\text { Little Bustard male / } \\
\text { Red-legged Partridge }\end{array}$ & YES & NO & YES & Primary \\
\hline $\begin{array}{l}\text { Great Bustard female / } \\
\text { Eurasian Stone-curlew }\end{array}$ & YES & YES & YES & Primary \\
\hline $\begin{array}{l}\text { Great Bustard male / } \\
\text { Eurasian Stone-curlew }\end{array}$ & YES & YES & YES & Primary \\
\hline $\begin{array}{l}\text { Great Bustard male / } \\
\text { Great Bustard female }\end{array}$ & NO & NO & NO & None \\
\hline $\begin{array}{l}\text { Red-legged Partridge / } \\
\text { Eurasian Stone-curlew }\end{array}$ & YES & NO & YES & Primary \\
\hline $\begin{array}{l}\text { Red-legged Partridge / } \\
\text { Great Bustard female }\end{array}$ & NO & NO & NO & None \\
\hline $\begin{array}{l}\text { Red-legged Partridge / } \\
\text { Great Bustard male }\end{array}$ & $\mathrm{NO}$ & YES & YES & Secondary \\
\hline
\end{tabular}

Figure 3. Overlap between probability density distributions of all the six species and sexes together in the PCA axis 1 (Cover availability; above) and the PCA axis 2 (Food availability; below). In gray: total overlap area (expressed as a percentage inside each plot). Different gray levels indicate different species.
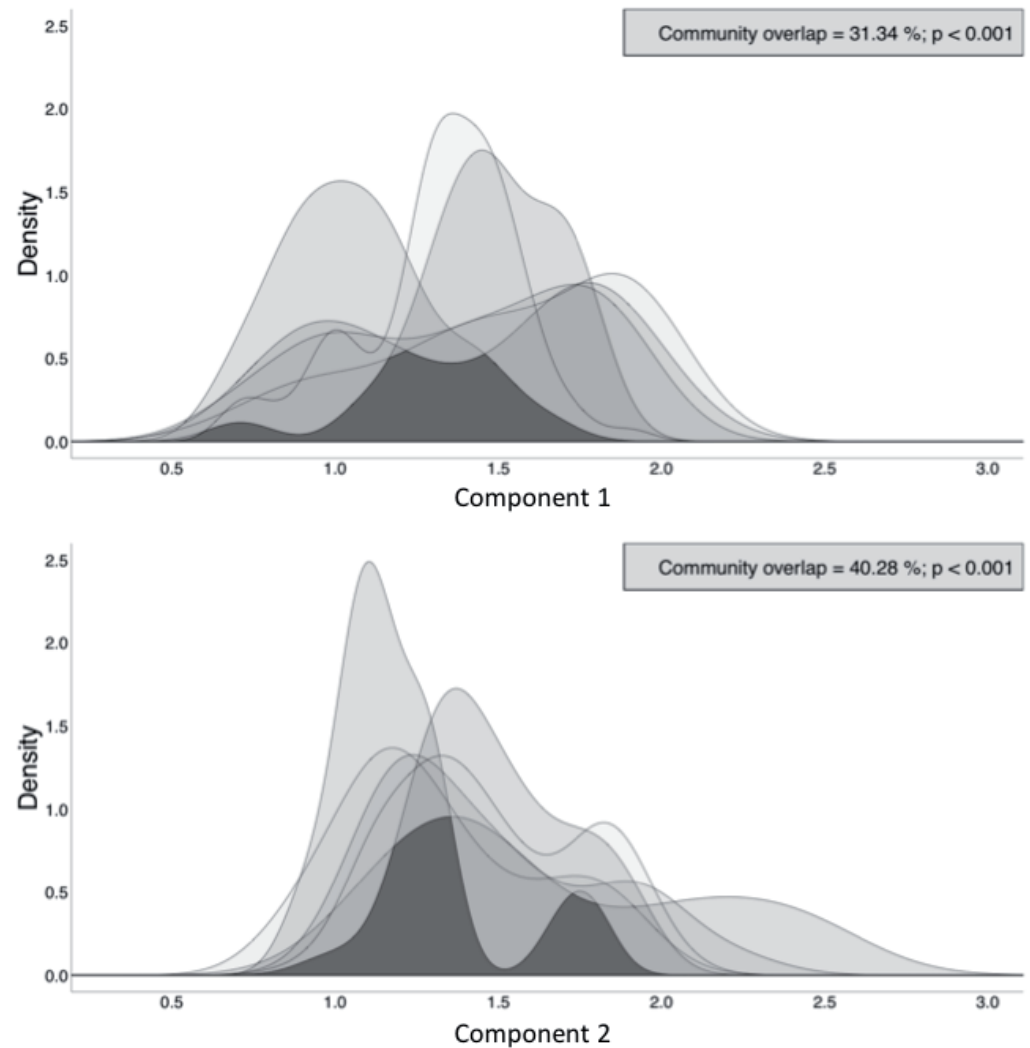
would allow interspecific coexistence at medium and large spatial scales (Chase and Leibold 2003), reducing spatial and trophic overlap among species. Furthermore, the microhabitat selection of these four species (and sexes) shows how they address the evolutionary trade-off between choosing foodrich habitats and those with high shelter availability in which predation risks are lower. The resolution of this trade-off is a function of their reproductive and life strategies and of their morphology (Morales and Traba 2009). In addition, this is, to the best of our knowledge, the first time that methods developed for evaluation of functional traits distance among species (Mouillot et al. 2005) has been used to estimate niche breadth, overlap, and segregation between pairs of set of birds and for an assemblage as a whole.

Thus, as predicted, the six set of birds generally showed primary resource partitioning according to their microscale habitat preferences (Table 5), the outcome being a small interspecific spatial and trophic overlap that enables their coexistence at larger scales. Because PCA component 1 accounted for $51 \%$ of the total variance explained, it can be interpreted as a primary resource for the steppe bird assemblage. It suggests that the species tend to minimise predation risks, even at the theoretical cost of lower access to food supplies, a finding that was particularly evident in the Great Bustard. Thus, this group of steppe birds appears to favour antipredator strategies over foraging strategies (Table 5), as has been shown in other species (Roberts and Liebgold 2008). Previous studies have demonstrated how predation pressure has been a driving factor in habitat use by foragers (e.g., Milinski and Heller 1978, Werner et al. 1983, Gilliam and Fraser 1987, Lima and Dill 1990, Kullberg 1998).

The Stone-curlew, the most cryptic of the study species (McMahon et al. 2010) and the hardest one to detect, was found at points along the gradient that were associated with areas with greater amounts of bare ground and low vegetation structure complexity, and thus with low cover availability. The Stone-curlew had a clear pattern of segregation with all the rest of the species in this primary shelter-visibility axis.

In turn, the Great Bustard, and particularly the females, tended to occupy points along the gradient that offered much more shelter, although they had the largest cover niche breadth in the assemblage. This may be explained in relation to the large size of this species (Table 1) and the need for incubating females to conceal themselves from potential predators. As Red-legged Partridges also require anti-predator concealment when nesting, they showed a big overlap in their distributions with female Great Bustard, but they occupied intermediate positions along the gradient, which seems to correspond with their smaller size (Table 1). Little Bustard females, however, showed clear niche segregation with Great Bustard females, in spite of their needs of concealment for nesting. As in females, Great and Little Bustard males seem to select different microhabitat locations, as shown by peaks and valleys in their density functions (Figure 2), which is reflected in the respective core areas (Figure 2).

With respect to intersexual differences, although male and female Little Bustards share a large extent of their core areas, males differed significantly from females in seeking less concealment than the latter, as might be expected in a species whose reproductive strategy involves a costly and conspicuous sexual display by males, both to attract females and for territory defence (Cramp and Simmons 1980, Jiguet and Bretagnolle 2014). Male Great Bustards also employ a conspicuous sexual display but they are much larger than Little Bustards (Table 1) and so do not find themselves forced to seek out more exposed locations (Olea et al. 2010).

The interspecific segregation detected on the second PCA axis, representing a food availability gradient, seems to be related to the selection of different feeding areas. This food availability gradient could be interpreted as a secondary resource for the steppe bird assemblage, because it accounted only for $22 \%$ of the total variance explained. Once again, the Stone-curlew occupies a different sub-space from those of the other species. This may be due to its different trophic requirements given that it is the only one of the four species that is almost exclusively insectivorous (Green et al. 2000, Giannangeli et al. 2004). The pair formed by Red-legged Partridge and Great Bustard male showed no primary partition, but it did show a secondary one resulting in niche segregation related to food availability. The other pairs showing secondary partitioning supported the previous results.

Only two pairs showed no partitioning at all: both sexes of Great Bustard and the female Great Bustard with Redlegged Partridge. As seen on axis 1, Red-legged Partridges and Great Bustards seems to select similar locations in relation to the food availability gradient, and overlap in their subspace, which may indicate a low level of interspecific competition between them due to a different resource partition (MacArthur and Levins 1967, Rosenzweig 1981). Although these species seem to share preferences for vegetation structure and therefore occupy areas offering similar cover and food availability, they probably differ in the use that each one makes of these resources, perhaps due to dietary differences (Cramp and Simmons 1980) or similar fitness values (Chesson 2000) that would allow them to coexist. On the other hand, both male and female Great Bustards overlapped in both primary and secondary resources, occupying sectors of the gradient where food availability was lower, and thus being more segregated from the other species. This may be due to a smaller importance of habitat differentiation for sexual display than for Little Bustards, and also to their much larger size (Table 1), which results in a smaller energy requirement (and thus, food intake) per unit of body mass due to the lower metabolic rate that is associated with larger body size. In the same sense, the segregation of core areas in the kernel density functions of Great and Little Bustard seems to be related to a differential microhabitat selection, which can facilitate coexistence, in large parts of their distribution ranges (Chase and Leibold 2003).

Remarkably, microhabitat preferences for the steppe bird assemblage showed no significant differences among localities. In this sense, the processes of microhabitat partition shown here, whose outcome is the segregation of realised niches (MacArthur and Levins 1967, Rosenzweig 1981), would be relatively independent of the ratio of resource 
density to competitor density, because this overlap would be predictably higher when this ratio is high (Gurd 2008). This means that segregation will be most marked where there is greater pressure on resources (if they are scarce or competitors are numerous, Gurd 2008).

In general, the present study suggests that competition may possibly have led to the development of dual mechanisms that allows coexistence. On the one hand, it may have resulted in primary resource partitioning by segregation of microhabitats, and hence of realised niches on the basis of an antipredatory strategy (Table 5). This should have occurred over evolutionary time between both closely related species, such as the two bustards, and distant species such as the Stone-curlew, involving marked character displacement (Dayan and Simberloff 2005). On the other hand, in the ecological scenario (sensu Gurd 2008), competition may have led to secondary resource partition (for example, in relation to diet) among species that overlap in their microscale spatial use and hence in their realised niches (Leibold 1998, Gurd 2008), as it occurs between the Great Bustard males and the Red-legged Partridge.

The need to conserve the typically Iberian agrarian mosaic in its entirety is evident if the species conservation is also to be ensured. When identifying and applying specific conservation measures, the steppe bird assemblage has often been represented by its flagship species, the Great Bustard, which has been prioritised by conservation programmes (Moreno et al. 2010). However, the present study shows, on the one hand, that different species differ clearly in their ecological niches and that it is therefore necessary to ensure that the needs of other steppe bird species are not overlooked (Moreno et al. 2010, Concepción and Díaz 2011). Indeed, the community overlap was about $36 \%$, and it was much lower than random expectations, indicating a low level of coincidence in the microhabitat selection of the entire assemblage. In addition, the results of niche breadth estimation showed that Red-legged Partridge, and especially Great Bustard, were the more adaptable (generalist) species, while the Stone-curlew and the Little Bustard seem to be the most restrictive (specialist) ones. Species with limited ranges of resource use are expected to be more sensitive to disturbance than generalists (Evans et al. 2005). On the other hand, this study allows the definition of the microhabitat features (based on the PCA axes) that are common to all the studied species (and sexes). The microhabitat structures where all species in this assemblage overlap coincide with those typical of fallows, which is the habitat type more clearly selected by Little Bustards (Morales et al. 2005, Delgado et al. 2010, Morales et al. 2013). This provides further support to the role of fallows as a key habitat for birds in agro-ecosystems (Delgado and Moreira 2000, McMahon et al. 2010, Traba et al. 2013). The maintenance and provision of this microhabitat structure should be considered a priority in the management of agricultural environments.

Acknowledgements. We thank D.J. Albendea, E. Carriles, M. Fernández, E.L. García de la Morena and M.A. Sanza for their valuable help during fieldwork. Several anonymous referees contributed to improve the manuscript at different stages. This paper is a contribution to projects CGL200406147-C02-01, CGL2004-06147-C02-02 and CGL2009$13029 / \mathrm{BOS}$ of the Spanish Ministry of Science, as well as to the REMEDINAL 2 (S-2009/AMB/1783) and 3CM. (S2013/ MAE-2719) networks of the CAM.

\section{References}

Buenestado F.J., P. Ferreras, M. Delibes-Mateos, F.S. Tortosa, J.A. Blanco-Aguiar and R. Villafuerte. 2008. Habitat selection and home range size of Red-legged Partridges in Spain. Agr. Ecosys. Environ. 126: 158-162.

Chase, J.H. and M.A. Leibold. 2003. Ecological Niches. Linking Classical and Contemporary Approaches. University of Chicago Press. Chicago and London.

Chesson, P. 2000. Mechanisms of maintenance of species diversity. Annu. Rev. Ecol. Syst. 31: 343-366.

Clere, E. and V. Bretagnolle. 2001. Food availability for birds in farmland habitats: biomass and diversity of arthropods by pitfall trapping technique. Rev. Ecol.-Terre Vie 56: 275-297.

Concepción, E.D. and M. Díaz. 2011. Field, landscape and regional effects of farmland management on specialist open-land birds: Does body size matter? Agr. Ecosys. Environ 142: 303-310.

Cramp, S. and K.E.L. Simmons (eds). 1980. The Birds of the Western Palearctic. Vols. II and III. Oxford University Press, Oxford, UK.

Dayan, T. and D. Simberloff. 2005. Ecological and community-wide character displacement: the next generation. Ecol. Lett. 8: 875894.

Davis, S.K. 2004. Area sensitivity in grassland passerines: effects of patch size, patch shape and vegetation structure on bird abundance and occurrence in southern Saskatchewan. Auk 121: 11301145 .

De Bello, F., C.P. Carmona, N.W.H. Mason, M.T. Sebastià and J. Lepš. 2013. Which trait dissimilarity for functional diversity: trait means or trait overlap? J. Veg. Sci. 24: 807-819.

De Juana, E. 2005. Steppe birds: a characterization. In: G. Bota, M. B. Morales, S. Mañosa, and J. Camprodon (eds.), Ecology and Conservation of Steppe-land Birds. Lynx Edicions, Barcelona. pp. 25-48.

Delgado, A. and F. Moreira. 2000. Bird assemblages of an Iberian cereal steppe. Agr. Ecosys. Environ 78: 65-76.

Delgado, M.P., J. Traba, E.L. García de la Morena and M.B. Morales. 2010. Habitat selection and density-dependent relationships in spatial occupancy by male Little Bustards Tetrax tetrax. Ardea 98: 185-194.

del Hoyo, J., A. Elliott, J. Sargatal, D.A. Christie and E. de Juana. (eds.). 2013. Handbook of the Birds of the World Alive. Lynx Edicions, Barcelona (retrieved from http://www.hbw.com/ node/53766 on 13 January 2015).

Devictor, V., J. Clavel, R. Julliard, S. Lavergne, D. Mouillot, W. Thuiller, P. Venail, S. Villéger and N. Mouquet. 2010. Defining and measuring ecological specialization. J. Appl. Ecol. 47: 1525 .

Evans, K.L., J.J.D. Greenwood and K.J. Gaston. 2005. Dissecting the species-energy relationship. P. Roy. Soc. B-Biol. Sci. 272: 2155-2163.

Geange, S.W., S. Pledger, K.C. Burns and J.S. Shima. 2011. A unified analysis of niche overlap incorporating data of different types. Methods Ecol. Evol. 2: 175-184 
Giannangeli, L., A. De Sanctis, R. Manginelli and F.M. Medina 2004. Seasonal variation of the diet of the Stone Curlew Burhinus oedicnemus distinctus at the island of La Palma, Canary Islands. Ardea 92: 175-184

Gilliam, J.F. and D. Fraser. 1987. Habitat selection under predation hazard: test of a model with foraging minnows. Ecology 68: 1856-1862.

Green, R.E. 1984. The feeding ecology and survival of partridge chicks (Alectoris rufa and Perdix perdix) on arable farmland in East Anglia. J. Appl. Ecol. 21: 817-830.

Green, R.E., G.A. Tyler and C.G.R. Bowden. 2000. Habitat selection, ranging behaviour and diet of the stone curlew (Burhinus oedicnemus) in southern England. J. Zool. 250: 161-183.

Guerrero I., M.B. Morales, J.J. Oñate, T. Aavik, J. Bengtsson, F. Berendse, L.W. Clement, C. Dennis, S. Eggers, M. Emmerson, C. Fischer, A. Flohre, F. Geiger, V. Hawro, P. Inchausti, A. Kalamees, R. Kinks, J. Liira, L. Meléndez, T. Pärt, C. Thies, T. Tscharntke, A. Olszewski and W.W. Weisser. 2011. Taxonomic and functional diversity of farmland bird communities across Europe: effects of biogeography and agricultural intensification. Biodivers. Conserv. 20: 3663-36813.

Gurd, D.B. 2008. Mechanistic analysis of interspecific competition using foraging trade-offs: implications for duck assemblages. Ecology 89: 495-505

Hromada M., L. Kuczyński, A. Kriśtin and P. Tryjanowski. 2003. Animals of different phenotype differentially utilize foraging niche - the Great Grey Shrike case study. Ornis Fennica 80: $71-$ 78.

Hubbell, S.P. 2001. The Unified Theory of Biodiversity and Biogeography. Princeton University Press, New Jersey, USA.

Jiguet, F. 2002. Arthropods in diet of Little Bustards Tetrax tetrax during the breeding season in western France. Bird Study 49: 105-109.

Jiguet, F. and Bretagnolle, V. 2014. Sexy males and choosy females on exploded leks: correlates of male attractiveness in the Little Bustard. Behav. Process 103: 246-255.

Krebs, J.R. and N.B. Davies. 1987. An Introduction to Behavioural Ecology. 2nd ed. Sinauer Associates, Sunderland, MA, USA.

Kullberg, C. 1998. Spatial niche dynamics under predation risk in the Willow Tit Parus montanus. J. Avian Biol. 29: 235-240.

Lane, S.J., J.C. Alonso, J.A. Alonso and M.A. Naveso. 1999. Seasonal changes in diet and diet selection of great bustards (Otis tarda) in north-west Spain. J. Zool. 247: 201-214.

Lane, S.J., J.C. Alonso and C.A. Martín. 2001. Habitat preferences of great bustard Otis tarda flocks in the arable steppes of central Spain: are potentially suitable areas unoccupied? J. Appl. Ecol. 38: 193-203.

Leibold, M.A. 1998. Similarity and local co-existence of species in regional biotas. Evol. Ecol. 12: 95-110.

Leibold, M.A., M. Holyoak, N. Mouquet, P. Amarasekare, J.M. Chase, M.F. Hoopes, R.D. Holt, J.B. Shurin, R. Law, D. Tilman, M. Loreau and A. Gonzalez. 2004. The metacommunity concept: a framework for multi-scale community ecology. Ecol. Lett. 7: 601-613.

Lima, S.L. and L.M. Dill. 1990. Behavioral decisions made under the risk of predation: a review and prospectus. Can. J. Zool. 68: 619-640.

López-Jamar, J., F. Casas, M. Díaz and M.B. Morales. 2010. Local differences in habitat selection by Great Bustards Otis tarda in changing agricultural landscapes: implications for farmland bird conservation. Bird Conserv. Int. 21: 328-341.
MacArthur, R.H. and R. Levins. 1967. The limiting similarity, convergence, and divergence of coexisting species. Am. Nat. 101: 377-385.

Mason, N.W.H., F. de Bello, J. Doležal and J. Lepš. 2011. Niche overlap reveals the effects of competition, disturbance and contrasting assembly processes in experimental grassland communities. J. Ecol. 99: 788-796

McMahon, B.J., D. Giralt, M. Raurell, L. Brotons and G. Bota. 2010 Identifying set-aside features for bird conservation and management in north-eastern Iberian pseudo-steppes. Bird Study 57: 289-300.

Milinski, M. and R. Heller. 1978. Influence of a predator on the optimal foraging behaviour of sticklebacks (Gasterosteus aculeatus). Nature 275: 642-644.

Morales, M.B., J.T. García and B.E. Arroyo. 2005. Can landscape composition changes predict spatial and annual variation of Little bustard male abundance? Anim. Conserv. 8: 167-174.

Morales, M.B., J. Traba, E. Carriles, M. P. Delgado and E. L. García de la Morena. 2008. Sexual differences in microhabitat selection of breeding Little Bustards Tetrax tetrax: ecological segregation based on vegetation structure. Acta Oecol. 34: 345-535.

Morales, M.B. and J. Traba. 2009. Compromisos adaptativos en la selección de hábitat de aves esteparias. In: H. Dopazo and A. Navarro (eds.), Evolución y Adaptación. 150 años después del origen de las especies. Obrapropia S.L. Valencia. pp. 304-313.

Morales, M.B., J. Traba, M.P. Delgado and E.L. García de la Morena. 2013. The use of fallows by nesting Little Bustards Tetrax tetrax females: Implications for conservation in mosaic cereal farmland. Ardeola 60: 3-15.

Moreira, F., R. Morgado and S. Arthur. 2004. Great bustard Otis tarda habitat selection in relation to agricultural use in Southern Portugal. Wildlife Biol. 10: 251-260.

Moreno, V., M.B. Morales and J. Traba. 2010. Avoiding over-implementation of agri-environmental schemes for steppe bird conservation: a species-focused proposal based on specialist criteria. $J$. Environ. Manage. 91: 1802-1809.

Mouillot, D., W. Stubbs, M. Faure, O. Dumay, J. Tomasini, J. Wilson and T. Chi. 2005. Niche overlap estimates based on quantitative functional traits: a new family of non-parametric indices. Oecologia 145: 345-353.

Olea, P., Casas, F., Redpath, S.M. and Viñuela, J. 2010. Bottoms up: great bustards use the sun to maximise signal efficacy. Behav. Ecol. Sociobiol. 64: 927-937.

Onrubia, A. and T. Andrés. 2005. Impact of human activities on steppic-land birds: A review in the context of western palearctic. In: G. Bota, M. B. Morales, S. Mañosa, and J. Camprodon (eds.), Ecology and conservation of steppe-land birds. Lynx Edicions, Barcelona. pp. 185-210.

R Development Core Team. 2011. R: A Language and Environment for Statistical Computing. $\mathrm{R}$ Foundation for Statistical Computing, Vienna. URL: http://www.R-project.org. ISBN3900051-07-0.

Roberts, A.M. and E.B. Liebgold. 2008. The effects of perceived mortality risk on habitat selection in a terrestrial salamander. Behav. Ecol. 19: 621-626.

Rosenzweig, M.L. 1981. A theory of habitat selection. Ecology 62 327-335.

Rosenzweig, M.L. and Z. Abramsky. 1986. Centrifugal community organization. Oikos 46: 339-348.

Rotenberry, J.T. and J.A. Wiens. 1980. Habitat structure, patchiness, and avian communities in North American steppe vegetation: a multivariate analysis. Ecology 61: 1228-1250. 
Rotenberry, J.T. and J.A. Wiens. 2009. Habitat relations of shrubsteppe birds: a 20-year retrospective. Condor 111: 401-413.

Sanderson, F.J., P. F. Donald and I.J. Burfield. 2005. Farmland birds in Europe: from policy change to population decline and back again. In: G. Bota, M. B. Morales, S. Mañosa, and J. Camprodon (eds.), Ecology and Conservation of Steppe-land Birds. Lynx Edicions, Barcelona. pp. 211-236.

Sanza, M.A., J. Traba, M.B. Morales, D. Rivera and M.P. Delgado. 2012. Effects of landscape, conspecifics and heterospecifics on habitat selection by breeding farmland birds: the case of Calandra Lark (Melanocorypha calandra) and Corn Bunting (Emberiza calandra). J. Ornithol. 153: 525-533.

Serrano, D. and C. Astraín. 2005. Microhabitat use and segregation of two sibling species of Calandrella larks during the breeding season: conservation and management strategies. Biol. Conserv. 125: 391-397.

StatSoft Inc. 2007. STATISTICA (Data Analysis Software System). Version 8.0. Tulsa, OK, USA.

Suárez, F., M.A. Naveso and E. De Juana. 1997. Farming in the drylands of Spain: the birds of the pseudosteppe. In: D.J. Pain and M. W. Pienkowski (eds.), Farming and Birds in Europe. London Academic Press, London. pp 297-330.

Traba, J., E.L. García de la Morena, M.B. Morales and F. Suárez. 2007. Determining high value areas for steppe birds in Spain: hot spots, complementarity and the efficiency of protected areas. Biodivers. Conserv. 16: 3255-3275.
Traba, J., M.P. Delgado, D. Albendea and M.B. Morales. 2012. Selección de macro y microhábitat del alcaraván común (Burhinus oedicnemus) en dos localidades madrileñas durante la estación reproductiva. Anu. Ornitol. Madrid 2009-2010: 23-40.

Traba, J., P. Sastre and M.B. Morales. 2013. Factors determining species richness and community composition in steppe birds of peninsular Spain. In: M. B. Morales and J. Traba (eds.), Steppe Ecosystems: Biological Diversity, Management and Restoration. NOVA Science Publishers, New York. pp. 29-46.

Tryjanowski P., T. Hartel, A. Báldi, P. Szymański, M. Tobolka, I. Herzon, A. Goławski, M. Konvička, M. Hromada, L. Jerzak, K. Kujawa, M. Lenda, M. Orłowski, M. Panek, P. Skórka, T. H. Sparks, S. Tworek, A. Wuczyński, and M. Żmihorski. 2011. Conservation of farmland birds faces different challenges in Western and Central-Eastern Europe. Acta Ornithol. 46: 1-12.

Werner, E.E., J.F. Gilliam, D.J. Hall and G.G. Mittelbach. 1983. An experimental test of the effects of predation risk on habitat use in fish. Ecology 64: 1540-1548.

Whittaker, R.H., S.A. Levin and R.B. Root. 1973. Niche, habitat and ecotope. Am. Nat. 107: 321-338.

Worton, B.J. 1989. Kernel methods for estimating the utilization distribution in home-range studies. Ecology 70: 164-168.

Received April 22, 2015

Revised June 17, 2015 Accepted August 27, 2015 